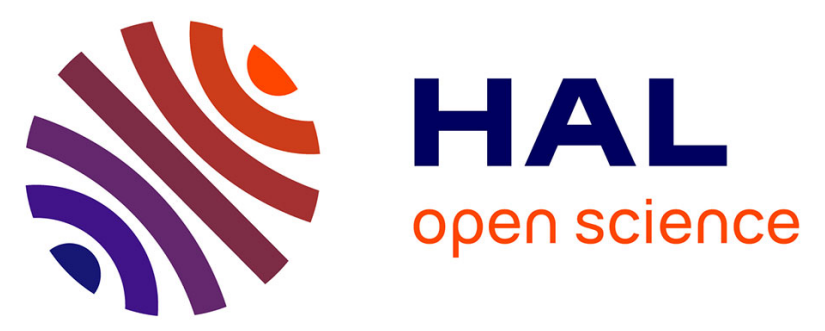

\title{
A Second-Generation Chameleon N-Heterocyclic Carbene-Borane Coinitiator for the Visible-Light Oxygen-Resistant Photopolymerization of Both Organic and Water-Compatible Resins
}

Bérengère Aubry, Daniel Subervie, Muriel Lansalot, Elodie Bourgeat-Lami, Bernadette Graff, Fabrice Morlet-Savary, Céline Dietlin, Jean-Pierre

Fouassier, Emmanuel Lacôte, Jacques Lalevee

\section{- To cite this version:}

Bérengère Aubry, Daniel Subervie, Muriel Lansalot, Elodie Bourgeat-Lami, Bernadette Graff, et al.. A Second-Generation Chameleon N-Heterocyclic Carbene-Borane Coinitiator for the VisibleLight Oxygen-Resistant Photopolymerization of Both Organic and Water-Compatible Resins. Macromolecules, 2018, 51 (23), pp.9730-9739. 10.1021/acs.macromol.8b01669 . hal-02007899

\author{
HAL Id: hal-02007899 \\ https://hal.science/hal-02007899
}

Submitted on 4 Jan 2022

HAL is a multi-disciplinary open access archive for the deposit and dissemination of scientific research documents, whether they are published or not. The documents may come from teaching and research institutions in France or abroad, or from public or private research centers.
L'archive ouverte pluridisciplinaire HAL, est destinée au dépôt et à la diffusion de documents scientifiques de niveau recherche, publiés ou non, émanant des établissements d'enseignement et de recherche français ou étrangers, des laboratoires publics ou privés. 


\section{A Second-Generation Chameleon N-Heterocyclic}

\section{Carbene-Borane Co-initiator for the Visible-}

\section{Light Oxygen-Resistant Photopolymerization of}

\section{both Organic and Water-Compatible Resins}

Bérengère Aubry, ${ }^{,, \#}$ Daniel Subervie, ${ }^{\rrbracket, \xi}$ Muriel Lansalot,${ }^{\S}$ Elodie Bourgeat-Lami, ${ }^{\S}$ Bernadette

Graff, ${ }^{, * \#}$ Fabrice Morlet-Savary, ${ }^{\not, \#}$ Céline Dietlin, ${ }^{\not, \#}$ Jean-Pierre Fouassier, ${ }^{\not, \#}$ Emmanuel

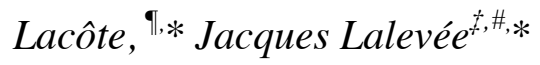

Université de Haute-Alsace, CNRS, IS2M UMR 7361, F-68100 Mulhouse, France

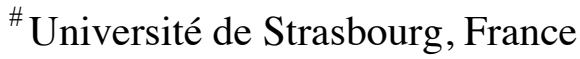

` Univ Lyon, Université Claude Bernard Lyon 1, CNRS, CNES, ArianeGroup, LHCEP, Bât.

Raulin, 2 rue Victor Grignard, F-69622 Villeurbanne, France

${ }^{\S}$ Univ Lyon, Université Claude Bernard Lyon 1, CPE Lyon, CNRS, C2P2, 43 Bd du 11

novembre 1918, F-69616 Villeurbanne, France

KEYWORDS: Boron, radical reactions, photochemistry, polymerization, NHC-Boranes. 
ABSTRACT: N-Heterocyclic Carbene-Boranes (NHC-Boranes, NHCBs) were recently described as efficient co-initiators for the visible light photopolymerization of hydroxyethyl methacrylate (HEMA) in the presence of water. In this work, a new, more water-soluble, NHCBorane: 2,4-dimethyl-1,2,4,5-tetrazol-3-ylidene borane has been synthesized, and its efficiency in three-component systems (dye (Acridine Orange), disulfide and NHC-Borane co-initiators) for the polymerization of methacrylate resins under visible light under air has been studied. In fluid resins this new photoinitiating system (PIS) gives better results than the one previously studied. More importantly, this system is competitive with the widely used type II system: camphorquinone/4-(dimethylamino) benzonitrile (DMABN) for the polymerization of methacrylate resins, but better for the photopolymerization of poly(2-hydroxyethyl methacrylate) leading to hydrogels, where the former PIS fails. The excellent ability of the NHC-Boranes and especially the new one, to be used as photopolymerization co-initiators has been analyzed by Laser Flash Photolysis (LFP). The rate constants for elementary reactions of the three boranes and their derived NHC-boryl radicals obtained by LFP correlated well with the molecular modeling data and show that the key for the observed reactivity is the ability of the tetrazolydinyl NHC-Borane to repair the peroxyl radicals formed by the reactions of the macroradicals with oxygen. 
TEXT.

Introduction: Visible-light-initiated photopolymerization ${ }^{1-7}$ has become a very important topic over the last few years, owing for example to the development of $3 \mathrm{D}$-printing ${ }^{8-10}$ Indeed, not only does it consume less energy than UV-initiated photopolymerizations, it also uses safer radiations and in principle allows the polymerization of UV-sensitive dyes. This has sparked a rush for new photoinitiating systems. ${ }^{11-15}$

In this context, N-Heterocyclic Carbene-borane complexes (NHCBs) are an interesting family of boron-based reagents ${ }^{16}$ that have found important applications in radical photopolymerizations. We showed that they were type II co-initiators for the UV- ${ }^{17,18}$ and visible light-initiated photopolymerization of acrylates in bulk or in an organic solvent. ${ }^{19}$ The introduction of a sulfide group at boron gave access to UV-initiated type I photolymerization, ${ }^{20}$ while the addition of one nitrogen atom to the NHC to the triazolylidene family made the corresponding NHC-Borane water-soluble and allowed us to photopolymerize hydroxyethyl acrylate and hydroxyethyl methacrylate (HEA and HEMA) in the presence of water (precipitation polymerization), with both $\mathrm{UV}^{21}$ and visible light. ${ }^{19}$ The same triazolylidene NHCBorane (see 2, Figure 1) also allows the photopolymerization of styrene in emulsion.22,23

Using NHCBs offers great advantages for the UV-photopolymerizations of acrylates in solution. As co-initiators or additives, they overcome oxygen inhibition, ${ }^{24}$ and the photopolymerizations proceed faster than when the standard, commercially available, UVtriggered benzophenone/aryl amine photoinitiating system is used. ${ }^{17,24}$ Herein we study deeper 
the visible-light photopolymerization of some acrylates and methacrylates, noticeably toward the polymerization of more or less fluid resins and its extension to the formation of hydrogels. An acrylic water-based resin was also considered to assess the scope of our co-initiators. This led us to introduce an optimized water-compatible (but still organosoluble) NHCB (3 in Figure 1). Based on modeling, physico-chemical characterizations and structure/reactivity relationships, we also give explanations as to why the new NHC-Borane is a better co-initiator than the previously introduced ones.

\section{Materials and Methods:}

- Chemicals. The NHCBs studied in this work are depicted in Figure 1.
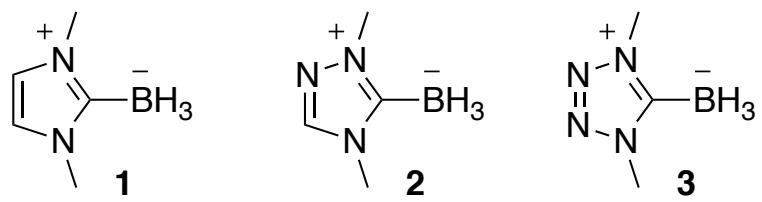

Figure 1: Chemical structures of the NHC-Boranes investigated.

Imidazolydinene-Borane $\mathbf{1}$ and Triazolydinene-Borane $\mathbf{2}$ were synthesized as previously reported in the literature..$^{25}$ Tetrazolydinene-borane $\mathbf{3}$ is a new compound. It was synthesized from commercially available N-methyl tetrazole, which was first methylated with the trimethyl oxonium tetrafluoroborate in dichloromethane to deliver a 9:1 mixture of 1,4- and 1,3dimethyltetrazolium tetrafluoroborate (see the Supporting Information for further details). ${ }^{26}$ The mixture of the salts was diluted in a 1:1 mixture of acetonitrile and THF at $-78^{\circ} \mathrm{C}$. The borane (first) and then potassium hexamethyldisilazane (KHMDS) were added. This allowed us to 
isolate $29 \%$ of $\mathbf{3}$, from which an X-ray diffraction structure was obtained (Figure 2). It should be noted that the carbene is not stable, therefore the base should absolutely be added last. Failure to do so resulted in very low yields.

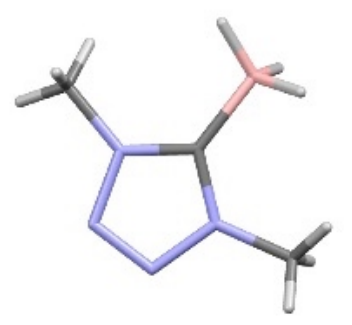

Figure 2. XRD structure of tetrazolydinene-type NHCB 3.

Diphenyl disulfide $(99 \%, 4)$ used was purchased from Sigma Aldrich and used as received, while 5 was prepared according to the literature..$^{22}$ Acridine Orange (99\%, AO) was also purchased from Sigma Aldrich, while Camphorquinone (>98\%, CQ) and (4-dimethylamino)benzonitrile ( $>98 \%$, DMABN) were purchased from Tokyo Chemical Industry (TCI-Europe) to be used as a reference for Type II photoinitiating system under visible light (Figure 3). The solvents used (acetonitrile, di(ethylene glycol) divinylether (DVE), THF and di-tert-butylperoxide) were purchased from Sigma Aldrich at the highest purity available and used as received. 


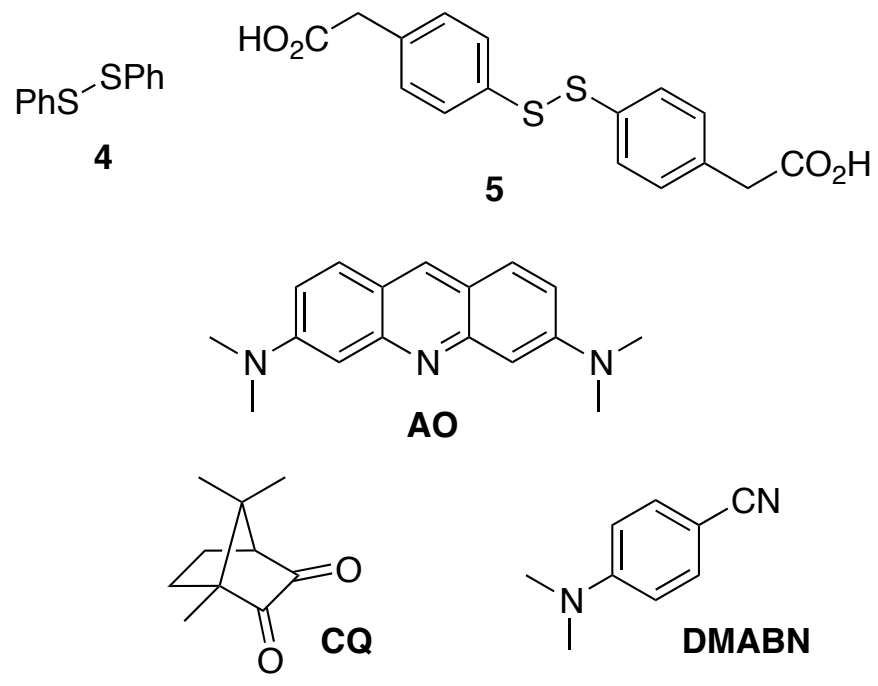

Figure 3. Structures of the reagents used in this work.

The efficiency of the photoinitiating systems (PISs) was studied on (meth)acrylate resins with different viscosities. Unless stated otherwise, all the monomers were obtained from Sigma Aldrich at the highest purity available and used as received. The first reference methacrylate blend (resin 1, Figure 4) was composed of 33 wt \% of 1,4-butanediol-dimethacrylate $(1,4-$ BDMA), $33 \mathrm{wt} \%$ of hydroxypropyl methacrylate (HPMA), and $33 \mathrm{wt} \%$ of urethanedimethacrylate oligomer 6. Its viscosity was 0.053 Pa.s. The second methacrylate resin (resin 2, Figure 4) had a higher viscosity of 5.7 Pa.s and was composed of $70 \mathrm{wt} \%$ of Bisphenol Aglycidyl methacrylate (Bis-GMA) and $30 \mathrm{wt} \%$ of triethylene glycol dimethacrylate (TEGDMA). A water-compatible acrylic resin (Ebecryl 605, obtained from Allnex, Resin 3) was also considered. It was composed of $75 \mathrm{wt} \%$ of bisphenol A epoxy diacrylate (bis-GA) and $25 \mathrm{wt} \%$ of tripropylene glycol diacrylate (TRPGDA). Its viscosity was 7.61 Pa.s. Finally, 2-hydroxyethyl methacrylate (HEMA) was purchased from Sigma Aldrich and lauryl acrylate monomer SR 335 was purchased from Sartomer. 

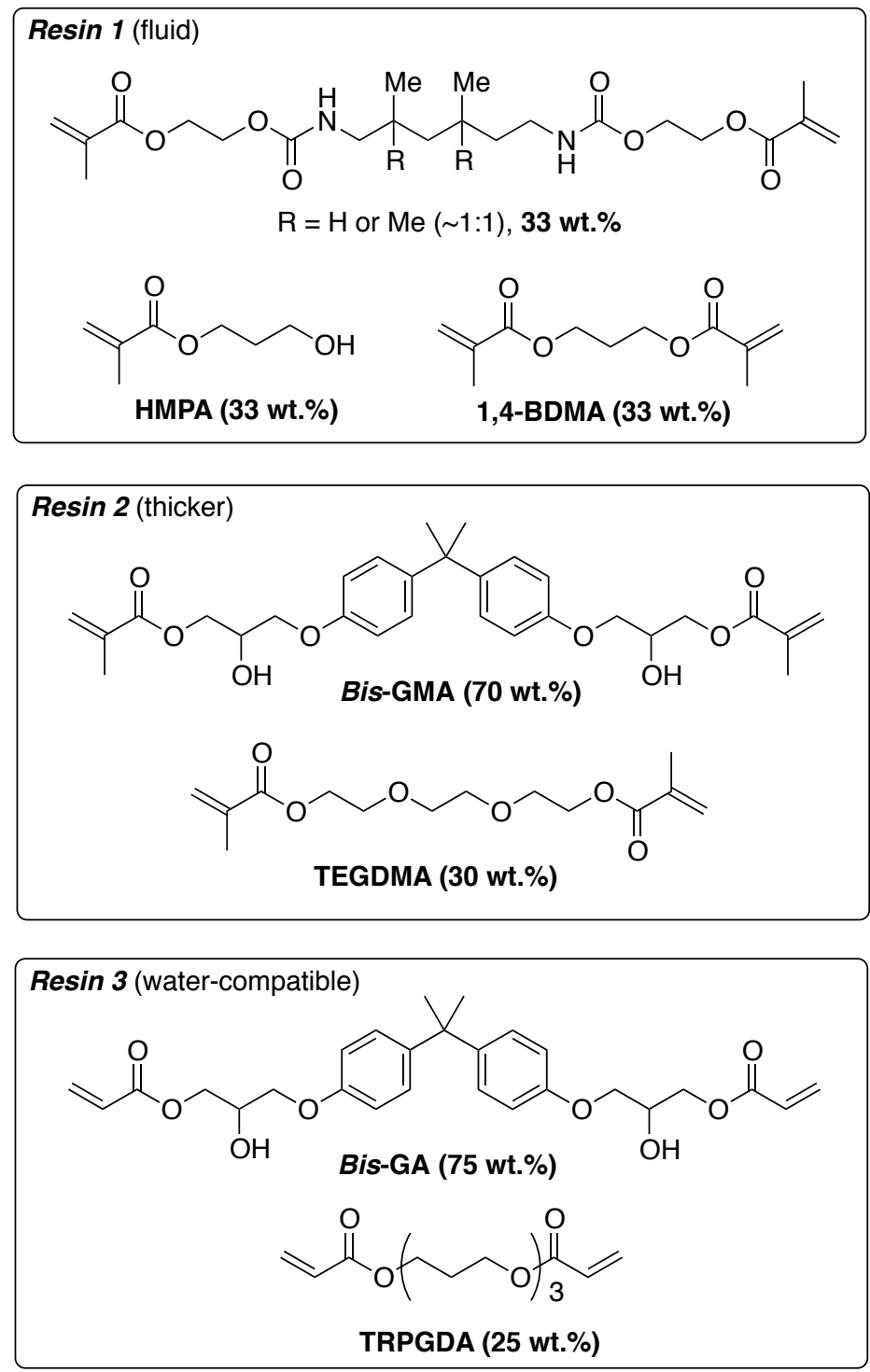

Figure 4. Compositions of the resins used in this work.

- Photopolymerization experiments. The experimental conditions for each photosensitive formulation are given in the captions of the figures. The photocurable formulations were deposited on a polypropylene film inside a $1.4 \mathrm{~mm}$ thick mold and were irradiated from the top with a LED @405 nm (M405LP1 - ThorLabs; light intensity around $115 \mathrm{mW.cm}{ }^{-2}$ at the sample surface). All the polymerizations were carried out under air at ambient temperature $\left(21-25^{\circ} \mathrm{C}\right)$. Irradiation was started at $\mathrm{t}=10 \mathrm{~s}$. A Jasco 6600 Real-Time Fourier Transformed Infrared 
Spectrometer (RT-FTIR) was used to follow the (meth)acrylate function conversion with time. The evolution of the $\mathrm{C}=\mathrm{C}$ double bond peak was continuously followed from 6110 to $6230 \mathrm{~cm}^{-1}$ (Figure S3).

- Computational procedure. The molecular orbital calculations were carried out with the Gaussian 03 package. Geometry optimizations ${ }^{27}$ were calculated at the uB3LYP/6-31+G* level of theory, and the geometries were frequency checked. The spin densities and electronegativities of the radicals were calculated from the time-dependent density functional theory at a B3LYP/6$31+\mathrm{G}^{*}$ level of theory on the relaxed geometries calculated at a $\mathrm{uB} 3 \mathrm{LYP} / 6-31+\mathrm{G}^{*}$ level of theory. The molecular orbitals involved in these transitions were extracted and the transition states for the addition of the NHC-boryl radicals onto methacrylates were determined.

- Laser Flash Photolysis (LFP). Nanosecond LFP experiments were carried out with a Qswitched nanosecond $\mathrm{Nd} / \mathrm{YAG}$ laser $\left(\lambda_{\text {exc }}=355 \mathrm{~nm}, 9 \mathrm{~ns}\right.$ pulses; energy reduced down to $10 \mathrm{~mJ}$, from Minilite Continuum) and an analyzing system consisting of a pulsed Xenon lamp, a monochromator, a fast photomultiplier and transient digitizer. ${ }^{5}$ The $t$-BuO• radicals were generated easily at $355 \mathrm{~nm}$ by the direct cleavage of di-tert-butylperoxide. The rate constants were determined by previously described procedures. ${ }^{28,29}$

- Atomic Force Microscopy (AFM). AFM measurements were carried out in a Bruker Multimode IV, with a Nanoscope V controller and an E "vertical" scanner, by the Peak Force Quantitative Nanomechanical Mapping (PF-QNM, Bruker) method. PF-QNM is a contact AFM mode, based on the force-volume method. In this method, force distance curves are collected by nanoindentation of the sample in a point-by-point mode. During measurement, the maximum (peak force) is controlled at each pixel to obtain force-distance curves that are then used as 
feedback signal. In this method, the loading and unloading force-distance curves are collected at a frequency of $2 \mathrm{kHz}$ at each position within the mapped area of the specimen. In parallel to topography images, informations on material elasticity (Young's modulus) and tip-to-surface adhesion were obtained. The modulus distribution for each sample surface was then plotted and fitted with a modified exponential Gaussian law; the reported moduli thus correspond to the center of the distributions whereas the errors correspond to their widths. ${ }^{30}$

All the experiments were carried out in air and at room temperature. $2 \mu \mathrm{m} \times 2 \mu \mathrm{m}(256 \times 256$ pixels at $0.8 \mathrm{~Hz}$ ) were taken at three different areas on the sample surface. To get relevant results, the cantilever and the tip geometry are taken into account in the PF-QNM measurements. Thus, a calibration procedure was first followed. All quantitative measurements were carried out with RTESPA-525 cantilever (Bruker, USA) with a spring constant of $200 \mathrm{~N} / \mathrm{m}$ and resonance frequency of $525 \mathrm{kHz}$, a width of $40 \mu \mathrm{m}$ and a length of $125 \mu \mathrm{m}$. Thanks to the Sader method (using the length, the width, the resonance frequency and the quality factor of the cantilever), ${ }^{31}$ the actual spring constant was determined and found to be around $225 \mathrm{~N} / \mathrm{m}$. Then, the deflection sensitivity (around $35 \mathrm{~nm} / \mathrm{V}$ ) was measured on a sapphire surface. Tip radius was calibrated against a polystyrene standard provided by Bruker. The measured value of the tip radius was 50 $\mathrm{nm}$. The Poisson's ratio was assumed to be equal to 0.3. For all experiments, samples were previously (at least half a day before) fixed on a sample holder with a double-sided tape.

\section{Results and Discussion}

- NHC-Borane co-initiators in the AO/disulfide initiated visible light photopolymerization of different (meth)acrylic resins. We selected the three NHC-boranes depicted in Figure 1 to carry out visible-light photopolymerizations of two methacrylic resins (resins 1 and 2, Figure 4), and 
one water-compatible acrylic one (resin 3, Figure 4). Resin 1 is fluid (0.053 Pa.s) and resin 2 is viscous (5.7 Pa.s). The three NHC-boranes differ by the number of nitrogen atoms present on the carbene: two in $\mathbf{1}$, three in $\mathbf{2}$ and four in $\mathbf{3}$. As a consequence, while $\mathbf{1}$ is organosoluble only, $\mathbf{2}$ and $\mathbf{3}$ are soluble in both water and organic phases. For the photopolymerization, we started with the photo-initiation conditions we had previously introduced. ${ }^{7}$ In this process, acridine orange (AO) absorbs a visible photon, leading to an excited state that is able to reduce aryl disulfides, such as 4 (step 1, Scheme 1). The resulting radical anion $\mathbf{4}^{--}$generates a thiyl radical upon cleavage of the S-S bond (step 2). The latter abstracts a H-atom from the NHC-borane (step 3). The resulting NHC-boryl radical adds to the monomer (step 4) and starts the polymerization.

Scheme 1. Mechanism of the visible light-photoinitiation with NHC-Boranes.

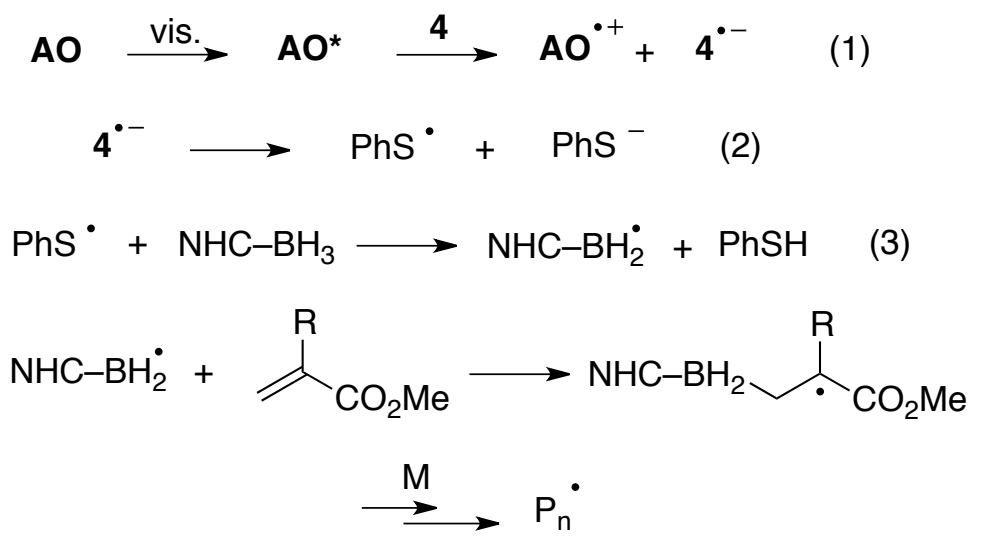

a) Methacrylic resins (resins 1 and 2). The photopolymerizations of resins 1 and 2 were carried out under air (1.4 mm thickness), through irradiation with a LED at $405 \mathrm{~nm}$. The evolution of the methacrylate content was followed by real-time FTIR spectroscopy at the wavenumber of the $\mathrm{C}=\mathrm{C}$ bond stretch (Figure 5A). For the sake of comparison, we also carried out the photopolymerizations with the standard camphorquinone (CQ) / DMABN system. ${ }^{32}$ 

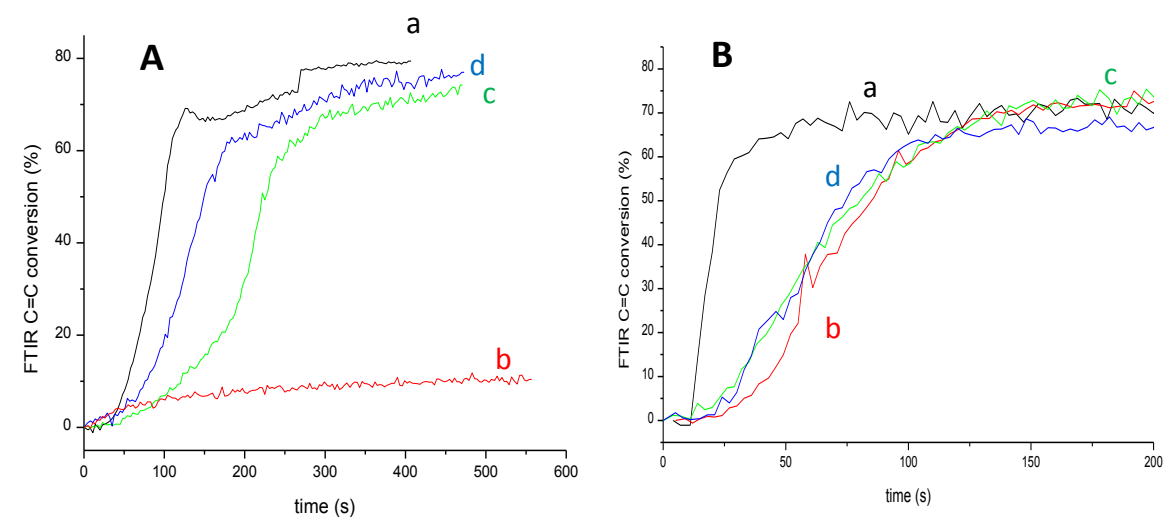

Figure 5. Photopolymerization profiles of the methacrylate resins 1 (A) and 2 (B). Conversion of the methacrylate function as a function of time for the three NHC-Boranes upon LED@405 nm irradiation under air $\left(1.4 \mathrm{~mm}\right.$ thick samples, start at $\left.\mathrm{t}=10 \mathrm{~s}, 115 \mathrm{~mW} / \mathrm{cm}^{2}\right)$. Photoinitiating systems: (curves a) CQ/DMABN (1/2 w/wt\%); (curves b) AO/4/1 (0.05/2/2 w/w/wt\%); (curves c) $\mathrm{AO} / 4 / 2(0.05 / 2 / 2 \mathrm{w} / \mathrm{w} / \mathrm{wt} \%)$; and (curves d) $\mathrm{AO} / 4 / 3(0.05 / 2 / 2 \mathrm{w} / \mathrm{w} / \mathrm{wt} \%)$.

- Fluid resin (resin 1): We observed that $\mathbf{1}$ completely failed to initiate the polymerization at $405 \mathrm{~nm}$ (curve b, Figure 5A), while triazolydinene and tetrazolydinene derivatives $\mathbf{2}$ and $\mathbf{3}$ led to conversions similar to that of the CQ/DMABN reference system (about 70\%, compare curves cd to curve a, Figure 5A and S4). Kinetically, the rate of polymerization with 2 was lower, and those of 3 and $\mathrm{CQ} / \mathrm{DMABN}$ were similar. However, only 0.05 wt.\% of AO were required, that is a 20-fold decrease compared to CQ (photopolymerization with only $0.05 \mathrm{wt} \% \%$ of CQ led to no polymerization). NHCB $\mathbf{1}$ is a good co-initiator for the polymerization of acrylates under both $\mathrm{UV}^{6}$ and visible light, ${ }^{7}$ but it apparently failed here to photopolymerize the methacrylic resin. In both cases, the photopolymerizations were faster with the more energetic UV light. ${ }^{17,24}$ Presumably, the flux of radicals is greater under UV. With visible light (405 nm) and a lower 
flux of initiating species, the photopolymerizations are more prone to oxygen inhibition, and may fail with methacrylates, which have lower $\mathrm{k}_{\mathrm{p}}$ 's.

- Viscous resin (resin 2): Contrary to what happened with the more fluid resin, all NHCBs behaved in the same way for the thicker resin 2 . They all led to efficient photopolymerizations (conversion near 70\%, curves b-d, Figure 5B). The same conversion was reached with $\mathrm{CQ} / \mathrm{DMABN}$, however the latter polymerization was faster (curve a), but similarly with 20-times more photoinitiator (again photopolymerization with only $0.05 \mathrm{wt} . \%$ of CQ was less efficient, leading to a $\mathrm{C}=\mathrm{C}$ conversion of approx. $50 \%$ with significant oxygen inhibition). Nevertheless, all polymerizations were quite fast (they were over after $125 \mathrm{~s}$ ) and the polymers obtained were tack-free and had the same aspect (see Figure S5).

Clearly, the only difference between the two resins derives from their viscosity. We therefore believe that NHCB $\mathbf{1}$ is more affected by oxygen that $\mathbf{3}$ (and to some extent $\mathbf{2}$ ). Indeed, oxygen inhibition is much higher in a fluid resin since the more fluid the resin, the faster its oxygen replenishment. With fluid resins it therefore becomes more difficult to consume the inhibiting oxygen. ${ }^{33}$ We will address this issue in depth later in this paper (vide infra).

b) Water-based resin (resin 3). Considering that $\mathbf{2}$ and $\mathbf{3}$ are hydrosoluble, we attempted to photopolymerize the acrylic resin Ebecryl 605 (resin 3). Resin 3 was mixed with 13 wt $\%$ of water, and the diphenyl disulfide 4 was changed to the hydrosoluble disulfide $5 .{ }^{10} \mathrm{~A}$ tack-free and rigid polymer was obtained after $150 \mathrm{~s}$ of mild irradiation at $405 \mathrm{~nm}$ (Figure 6). The final conversion was similar for the two formulations, again around 70\%, although the polymerization profiles have an increased noise due to the presence of water. Gratifyingly, while insoluble in water, NHCB 1 could be dissolved in the resin before the addition of water. The ensuing 
photopolymerization was similar to the previous two, albeit somewhat less rapid (it took roughly 100 s more - nearly twice the time - to reach the same conversion).

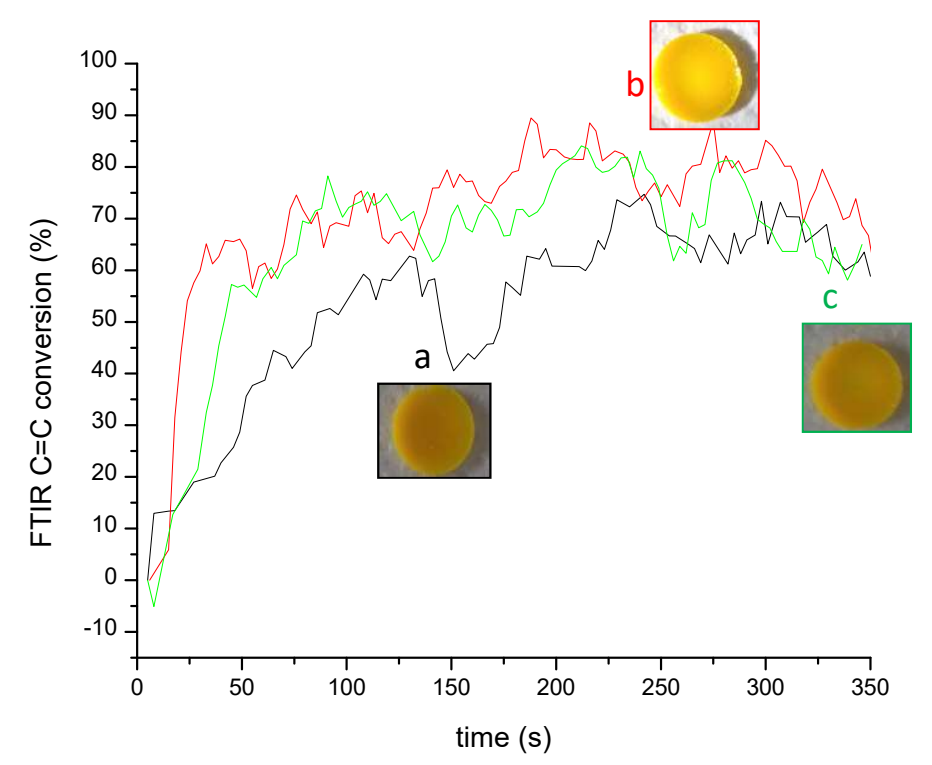

Figure 6. Photopolymerization profiles of Ebecryl 605 in the presence of water (ca. 15 wt $\%$ ). Conversion of the methacrylate function as function of time for the three NHC-Boranes upon LED@405 nm irradiation under air (1.4 mm thick samples, start at $\left.\mathrm{t}=10 \mathrm{~s}, 115 \mathrm{~mW} / \mathrm{cm}^{2}\right)$ with different PIS formulation compositions: AO/5/NHCB $(0.05 / 2 / 2 \mathrm{w} / \mathrm{w} / \mathrm{wt} \%)$ in Ebecryl $605+$ water; (curve a) NHCB is $\mathbf{1}$, (curve b) NHCB is $\mathbf{2}$, (curve c) NHCB is $\mathbf{3}$.

Overall, our three NHCBs led to the photopolymerization under visible light of both methacrylic resins and a water-based acrylic one. Together with the much improved sensitivity of the initiator (20 times less AO is needed than CQ), this is a clear advantage over the CQ-based initiator, which is not stable enough for polymerization in water-based resins. 
c) Hydrogel synthesis. Given the promising results with the Ebecryl-based water blend, we investigated whether we could prepare hydrogels. ${ }^{34}$ For this, the three-component systems $[\mathrm{AO} / \mathbf{5} / \mathrm{NHCB}]$ were used for the polymerization of HEMA in water $(50: 50 \mathrm{w} / \mathrm{wt} \%$, note that NHCB 1 is soluble in the mixture). Contrary to what precedes, in that case the polymerization was carried out under argon. To really see the influence of the NHCB structure only, the formulations contained in a standard vial were degassed before irradiation by bubbling argon for 5 min. Gratifyingly, hydrogels were obtained after 2h15 min of LED@405nm irradiation (110 $\mathrm{mW} / \mathrm{cm}^{2}$ ) for all the starting formulations. The commercially available plain vials are transparent to visible light. The polymerization took longer because the initial formulation is thicker and the reactive functions more diluted. A change of the viscosity was nonetheless clearly observed during the polymerizations. The hydrogels were homogeneous, and no monomer phase was observed on the upper surface (Figure 7b and S6a), suggesting that conversion was higher that $80 \%$. A more accurate value cannot be obtained because the IR signals suffer from noise because of the presence of water. Nevertheless, it is possible that some monomer remained trapped inside the polymer network. The water content for the hydrogels synthesized was determined by thermogravimetric measurements (see Figures S7-S9). From NHCB 1 a gel containing 46\% water was obtained, while $\mathbf{2}$ and $\mathbf{3}$ led to gels containing respectively $39 \%$ and $35 \%$ water. The NHCB PIS's therefore solve the limitations of the more well-known Type II PIS "CQ/amine" for visible-light polymerization. Indeed, as mentioned before, the latter system is not stable in water. In our hands it led to a non-homogeneous hydrogel with two phases (Figure S6b). This further extends the scope of radical photopolymerizations allowed by NHCB initiators which perform better than the pioneering visible light PIS. Indeed, beyond hydrogels which have important biomedical applications (e. g. contact lenses, artificial cornea, tissue regeneration, etc.) one can 
envisage access to microgels. In both cases, temporal and spatial control is expected from the use of light.

Figure 7. Polymerization of HEMA in water using AO/3/5 leading to a hydrogel under LED irradiation (2h15) at $405 \mathrm{~nm}$.

d) Formulations stability. The stability of the formulations before polymerization is an important factor to consider when choosing a PIS and a more powerful PIS would not be chosen if it is not shelf-stable over extended periods of time. Therefore, several formulations based on the NHCBs were stored for one month in a dark box at room temperature and under air. The photopolymerization profiles of resin 1 under the same conditions as before, but with the aged formulations, were obtained (dotted lines) and compared to those using the pristine PISs (plain lines, Figure 8). Within the experimental errors, the profiles were the same for all samples. This shows the high stability of the new Boron-based PISs. 


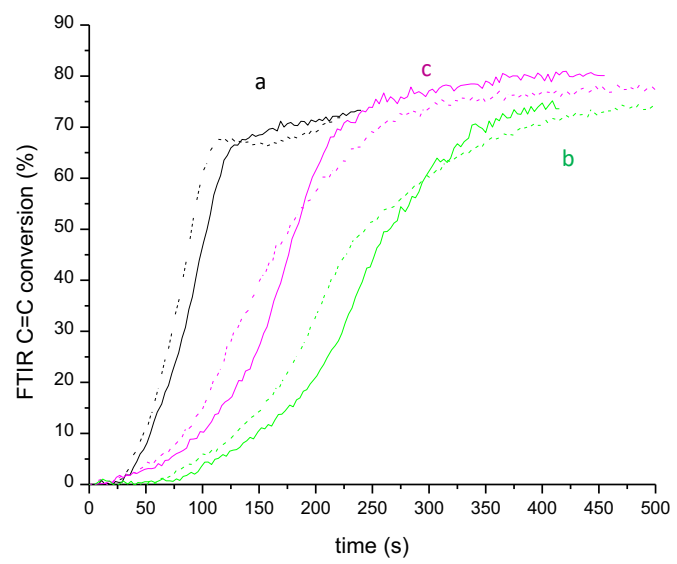

Figure 8. Photopolymerization profiles upon LED@405 nm irradiation of resin 1 under air. Conversion of the methacrylate function as a function of time (start at $\mathrm{t}=10 \mathrm{~s}, 115 \mathrm{~mW} / \mathrm{cm}^{2}$ ) with pristine (plain lines) and one-month aged (dotted lines) formulations. $1.4 \mathrm{~mm}$ thick samples were used. Photoinitiating systems: (a) CQ/DMABN (1/2 w/wt $\%)$, (b) 2/AO/4 (0.05/2/2 $\mathrm{w} / \mathrm{w} / \mathrm{wt} \%)$, (c) 3/AO/4 (0.05/2/2 w/w/wt $\%)$.

e) Resistance to solvent (acetonitrile) and Young modulus. We finally wished to prove that the Boron-based PISs did not lead to materials with lower final properties compared to standard PISs. The efficiency of the resin photopolymerization is measured by the strength of the crosslinked network. The cured polymers obtained from resin 1 and the photoinitiating systems 2/AO/4, 3/AO/4 and CQ/DMABN were first immersed in acetonitrile (ACN) for $2 \mathrm{~h} 30$ to determine their resistance to solvent. Less than $10 \%$ swelling was observed after that time, and the polymers re-isolated were still hard when touched. They were then oven-heated at $50{ }^{\circ} \mathrm{C}$ for several hours. When part of the material is dissolved or chipped away by immersion in the solvent, a mass loss is registered after filtration and drying, and the more resistant the material, the lower the mass loss (and therefore the better the polymerization). The ratio between the mass 
of polymer remaining after several hours in the oven and the mass of the cured polymer before immersion was determined for the three samples. After immersion/filtration and 2.5 days in the oven at $50{ }^{\circ} \mathrm{C}$ the weight loss was equal to $6.2 \%$ for the reference formulation (CQ/DMABN), and $6.7 \%$ and $9.3 \%$ for the $(\mathbf{3} / \mathrm{AO} / \mathbf{4})$ and $(\mathbf{2} / \mathrm{AO} / 4)$ photoinitiator systems respectively. All the materials therefore exhibit a good resistance to ACN. The surfaces of the samples obtained without NHCB (that is, where the PIS is AO/4 only) are not well polymerized and too tacky. Their weight loss was also larger (17.9\%), illustrating the beneficial effect of the NHCB.

In parallel experiments, the mechanical properties (Young modulus) of the materials obtained from the photopolymerizations were studied by AFM. The Derjaguin-Müller-Toparov (DMT) fit model was used to calculate the elastic moduli (E) of the different samples. The Young's moduli maps of the same previous samples are shown in Figure 9. Three measurements per sample have been achieved and the Young's modulus average was determined thanks to the maps (Figure 9) and histograms (see Figure S10). The Young's modulus for all three polymers was found to be around $2 \mathrm{GPa}(2.0 \pm 0.2$ for $\mathrm{CQ} / \mathrm{DMABN} ; 1.7 \pm 0.2$ for $\mathbf{2} / \mathrm{AO} / \mathbf{4}$, and $1.9 \pm 0.2$ for $\mathbf{3} / \mathrm{AO} / \mathbf{4})$ and their surface was homogeneous on a $2 \mu \mathrm{m} \times 2 \mu \mathrm{m}$ area. Indeed the rugosity is not more than 2 $\mathrm{nm}$ for the three samples according to the height maps. Therefore the polymers obtained from the Boron-based PIS have the same properties as the sample obtained using the established reference system. This again means that the polymerizations are robust. 

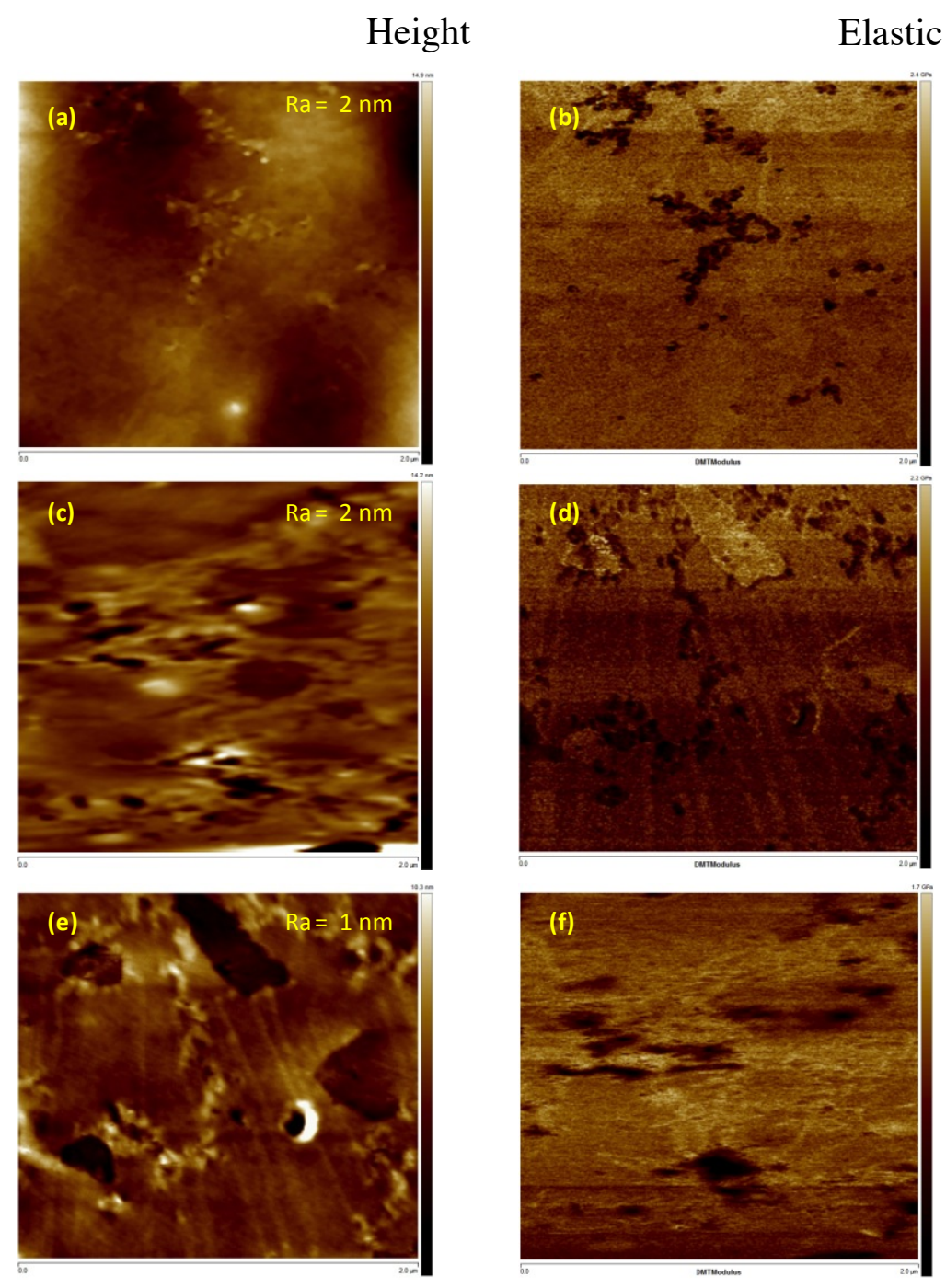

Figure 9. Representative topography $(2 \mu \mathrm{m} \times 2 \mu \mathrm{m})$ maps (left column) and DMT modulus (2 $\mu \mathrm{m} \times 2 \mu \mathrm{m}$ ) (right column) obtained with Peak Force QNM from cured resin 1 after LED irradiation @405 nm under air. The PISs were the following: (a) and (b) CQ/DMABN (1/2 w/wt $\%$ ), (c) and (d) 2/AO/4 (0.05/2/2 w/w/wt $\%)$; and (e) and (f) 3/AO/4 (0.05/2/2 w/w/wt $\%$ ). The height color scale represents the height from 0 to $14.9 \mathrm{~nm}$, from 0 to $14.2 \mathrm{~nm}$ and from 0 to $10.3 \mathrm{~nm}$ for (a), (c) and (e), respectively. The DMT modulus color scale represents the modulus from 0 to $2.4 \mathrm{GPa}$, from 0 to $2.2 \mathrm{GPa}$ and from 0 to $1.7 \mathrm{GPa}$ for (b), (d) and (f), respectively. 
- Why does tetrazolydinene-borane $\mathbf{3}$ perform better than $\mathbf{1}$ and $\mathbf{2}$ ? A structure/reactivity relationship for NHCBs. In this part we sought to better understand why NHCB 3 performs better than $\mathbf{1}$ and - albeit to a lesser extent- than $\mathbf{2}$, especially for the photopolymerization in a fluid resin (i.e. under severe oxygen inhibition conditions). We therefore determined the rate constants of the elementary steps involved in the polymerization. Molecular orbitals calculations have also been carried out to gather additional information on the reactivity of the NHC-boryl radicals.

a) Reductive power of the $\mathrm{NHC}$-Boranes. The first property we considered is the hydridic nature of the B-H bonds. To do this, we evaluated the reductive power of the three NHCBs toward the silica-activated reduction of aldehydes (Scheme 2 ) ${ }^{35}$ These were added to a slurry of 4-bromobenzaldehyde and silica gel in ethyl acetate at room temperature. The reaction was stopped after 2 hours and the conversion was measured by NMR using dichloromethane as an internal standard.

Scheme 2. Evaluation of the hydridic character of NHC-Boranes<smiles>O=Cc1ccc(Br)cc1</smiles><smiles>[B]O[Ga]OC(=O)OCC</smiles><smiles>OCc1ccc(Br)cc1</smiles><smiles>[BH3-]c1n(C)cc[n+]1C</smiles>
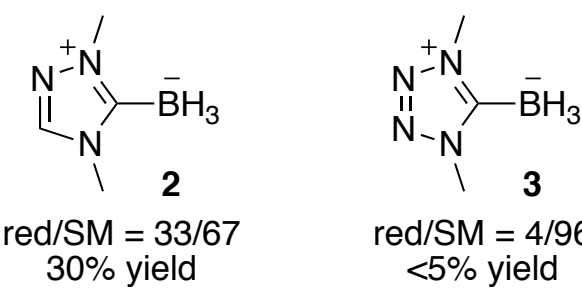

$\mathrm{red} / \mathrm{SM}=4 / 96$ $<5 \%$ yield 
The single-point kinetic showed that while the conversion and yield were nearly quantitative with $\mathbf{1}$, the reaction was much less rapid with $\mathbf{2}$, and mostly not started with $\mathbf{3}$. This shows that the hydridic character of the $\mathrm{H}$ atoms of NHCBs is much weaker in the triazolydinene and especially tetrazolydinene series, which is likely a reflection of their weaker $\sigma$-donating character. Clearly, this is a function of the number of nitrogen atoms in the ring.

b) Rate constants of the elementary steps involving the NHC-boryl radicals. The rate constants for the main elementary radical steps involving $\mathbf{3}$, and its derived $\mathrm{NHC}-\mathrm{BH}_{2} \bullet$ radical $\mathbf{3} \bullet$ have been determined in acetonitrile by LFP. The values obtained have been compared to the ones previously found for $\mathbf{1} \bullet$ and $\mathbf{2} \cdot{ }^{21,24}$

- Formation of the NHC-boryl radicals by H-atom abstraction from the NHC-Borane: The first step in the type II radical photopolymerization is the formation of the initiating radical from the co-initiators. This is usually achieved via the excited state of benzophenone ${ }^{3}$. As the reactivity of the excited state of benzophenone is similar to that of alkoxyl generated radicals (Eq. 1), the rate of the former reaction can be approximated by that of the latter. NHC-Boryl radical 3• was easily generated in the LFP apparatus via abstraction of a hydrogen atom from 3 , by a $t$-BuO• radical (see equation 2), using a method previously introduced. ${ }^{5}$ The latter radical was generated by UV photocleavage of di-tert-butyl peroxide (equation 1). Because the $t$-BuO $\bullet$ radical does not absorb light above $300 \mathrm{~nm}$, it is transparent for LFP.

$$
\begin{aligned}
& t-\mathrm{BuO}-\mathrm{O} t-\mathrm{Bu}+\mathrm{h} v \rightarrow t-\mathrm{BuO} \bullet \\
& t-\mathrm{BuO} \bullet+\mathrm{NHC}-\mathrm{BH}_{3} \rightarrow t-\mathrm{BuOH}+\mathrm{NHC}-\mathrm{BH}_{2} \bullet
\end{aligned}
$$


An abstraction of hydrogen rate constant $\left(\mathrm{k}_{\mathrm{H}}\right)$ was extracted from the rising time of $\mathbf{3} \bullet$, which can be directly observed in LFP experiment (Figure 10a), the associated procedure has been described in detail in ${ }^{4-5}$. It corresponds to the rising time for the $3 \bullet$ signal after the pulse at 355 $\mathrm{nm}$ using the Stern-Volmer law (Figure S11). The rising time only corresponds to the formation of 3• as $t$ - $\mathrm{BuO} \bullet$ does not absorb or emit above $300 \mathrm{~nm}$. The $\mathrm{H}$-abstraction rate constant found for $3\left(\mathrm{k}_{\mathrm{H}} \approx 2.7 \pm 1.5 \times 10^{8} \mathrm{M}^{-1} \mathrm{~s}^{-1}\right)$ is similar to those of the previous NHCBs (see Table 1$)$. The reactivity of the tetrazole borane toward $\mathrm{H}$-abstraction is thus comparable to those of the triazole and imidazole boranes $\mathbf{1}$ and $\mathbf{2}$. This shows that the hydridic character of the $\mathrm{B}-\mathrm{H}$ bond is, at best, a secondary factor to explain the reactivity of the NHCBs as photopolymerization initiator (see also below). The absorption spectrum of $\mathbf{3} \bullet$ has been determined by recording the maximum absorption reached $2.8 \mu \mathrm{s}$ after the pulse (Figure $10 \mathrm{~b}$ ).
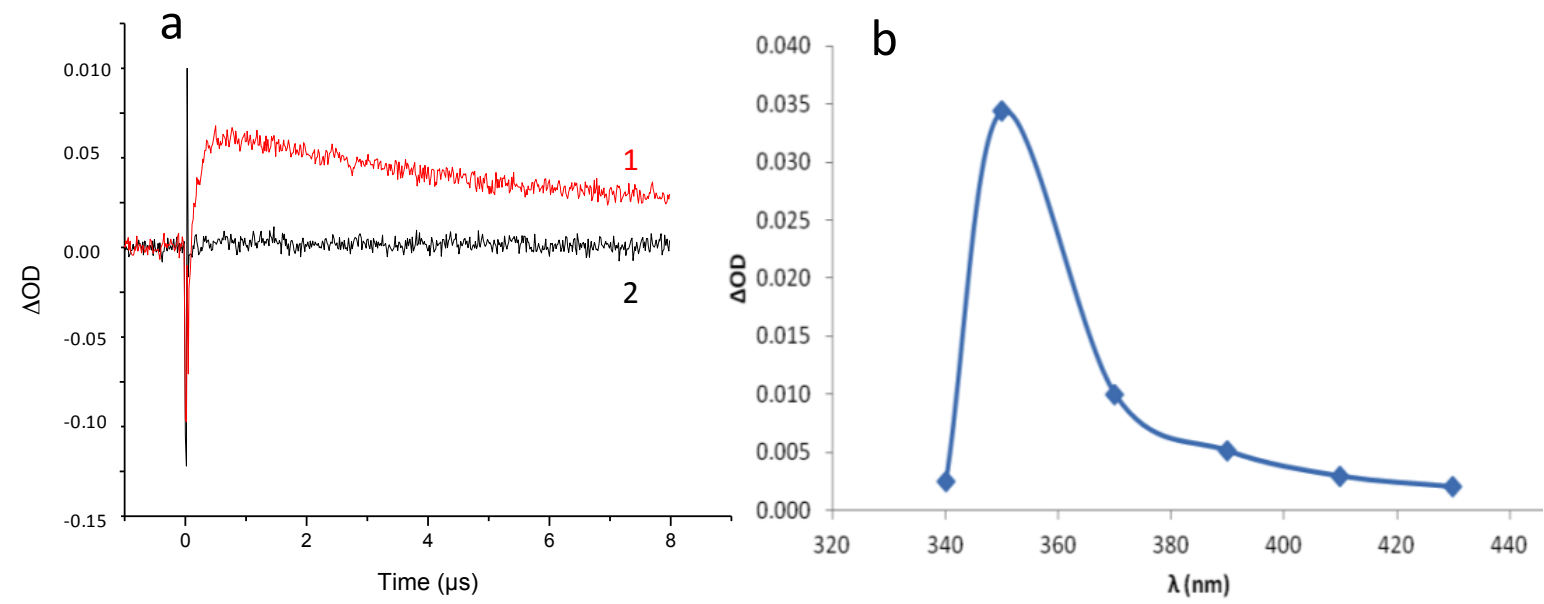

Figure 10. a) Kinetics corresponding to the formation of $\mathbf{3}^{\bullet}$ from $\mathbf{3}$ at $\lambda=350 \mathrm{~nm}$ (in acetonitrile/di-tert-butylperoxyde 50/50 v/v); the black curve (2) shows the signal obtained before addition of $\mathbf{3}$ (no absorption of $t$ - $\mathrm{BuO} \bullet$ at $350 \mathrm{~nm}$ ); the red curve (1) corresponds to the 
signal obtained after addition of $\mathbf{3}([\mathbf{3}]=1.86 \mathrm{M})$. b) Time-resolved UV/Vis spectrum of $\mathbf{3} \bullet$ in ditert-butylperoxide/acetonitrile for $\mathrm{t}=2.8 \mu \mathrm{s}$.

- Reactivity of the NHC-boryl radicals towards $\mathrm{O}_{2}$, an electron-poor alkene (lauryl acrylate) and an electron-rich alkene (diethylene glycol divinylether): The next important elementary steps of the photopolymerization are i) the compatibility of the initiating radical with dioxygen (which traps it), and ii) its addition to the monomer. To better understand the NHCB-co-initiated photopolymerizations of the methacrylate resins under air (see part 3.1), we determined first the rate constants for the addition of $3 \bullet$ to dioxygen (equation 3) and to lauryl acrylate (equation 4). The addition of 3• onto diethylene glycol divinylether (DVE), an electron-rich alkene was also studied. The results were compared to those obtained for $\mathbf{1} \bullet$ and $\mathbf{2} \cdot{ }^{21,24}$

$\mathrm{NHC}-\mathrm{BH}_{2} \bullet+\mathrm{O}_{2} \rightarrow \mathrm{NHC}-\mathrm{BH}_{2}-\mathrm{OO} \bullet$

$\mathrm{NHC}-\mathrm{BH}_{2} \bullet+\mathrm{R}-\mathrm{CH}=\mathrm{CH}_{2} \rightarrow \mathrm{NHC}-\mathrm{BH}_{2}-\mathrm{CH}_{2}-\mathrm{CH}(\bullet)-\mathrm{R}$

The rate constants were obtained by the determination of the decay time of the NHC-boryl radical signals measured for different concentrations of the quencher (either the monomer or dioxygen) (Figure 11a-b). The Stern-Volmer plot (Figure 11c) of the inverse of the lifetime as a function of the quencher concentration gave the rate constant of addition. For the NHC-boryl radicals addition to the olefin, all measurements were performed under a $\mathrm{N}_{2}$-saturated atmosphere with solutions degassed for at least 10 minutes prior to use, to avoid any unwanted reaction of the radicals with dioxygen. The kinetics data are again gathered in Table 1. Interestingly, $\mathbf{3 \bullet}$ reacts one order of magnitude less rapidly with $\mathrm{O}_{2}$ than $\mathbf{1} \bullet$ and $\mathbf{2} \bullet\left(\mathrm{k}_{\mathrm{O} 2}=1.9 \times 10^{8}\right.$ 
$\mathrm{M}^{-1} \mathrm{~s}^{-1}$ vs. $\sim 10^{9} \mathrm{M}^{-1} \mathrm{~s}^{-1}$, see Table 1). 3• is also a nucleophilic species that adds at least 10 times more rapidly to the electron-poor acrylate than to the electron-rich DVE. The rate constant for addition to lauryl acrylate for $\mathbf{3} \bullet$ is lower by a factor 4 compared to $\mathbf{2} \bullet$ and 10 compared to $\mathbf{1} \bullet$.

Table 1. Rate constants for hydrogen atom abstraction from NHC-boranes 1-3 and for some reactions of the resulting radicals: addition to lauryl acrylate, ethyl vinyl ether (EVE) or DVE and dioxygen.

\begin{tabular}{|c|c|c|c|c|}
\hline $\begin{array}{l}\text { NHC- } \\
\text { Borane }\end{array}$ & $\begin{array}{l}\mathrm{k}_{\mathrm{H}}(t-\mathrm{Bu}-\mathrm{O} \bullet) \mathrm{x} \\
10^{7} \mathrm{M}^{-1} \mathrm{~s}^{-1}\end{array}$ & $\begin{array}{c}\mathrm{k}_{\mathrm{add}}\left(\mathrm{O}_{2}\right) \\
\times \quad 10^{7} \mathrm{M}^{-1} \mathrm{~s}^{-1}\end{array}$ & $\begin{array}{l}\mathrm{k}_{\mathrm{add}} \text { of } \mathrm{B} \bullet \text { on electron- } \\
\text { poor alkene } \\
\text { x } 10^{6} \mathrm{M}^{-1} \mathrm{~s}^{-1}\end{array}$ & $\begin{array}{c}\mathrm{k}_{\mathrm{add}} \text { of } \mathrm{B} \bullet \text { on } \\
\text { electron-rich alkene } \\
\mathrm{x} 10^{6} \mathrm{M}^{-1} \mathrm{~s}^{-1}\end{array}$ \\
\hline 1 & 26 & 150 & $38^{\mathrm{a}}$ & $<0.1^{\mathrm{c}}$ \\
\hline 2 & 14 & $>60$ & $17^{\mathrm{a}}$ & $<0.03^{\mathrm{d}}$ \\
\hline 3 & $27 \pm 15$ & $19 \pm 7$ & $3.8 \pm 0.8^{b}$ & $<0.09^{\mathrm{d}}$ \\
\hline
\end{tabular}

${ }^{a}$ Value taken from ref. 9 with methyl acrylate; ${ }^{b}$ Lauryl acrylate was used ; ${ }^{c}$ Value taken from ref. 9 with EVE; ${ }^{\text {d }}$ DVE was used.

The problem of oxygen inhibition is not acute in viscous resins, because the concentration of dioxygen is limited by diffusion. From the point of view of the addition to the monomer, $\mathbf{3}$ did not underperform despite its relatively slower addition rate. We know from previous work that the NHC-Boryl addition step is not rate-determining. ${ }^{36}$ That explains why all NHCBs performed similarly in that case. This is compounded by the diffusion of the NHC-Boryl radicals themselves in the resins, which is certainly slower than their addition to the double bonds (which remains rapid in absolute), independently of the resin. Therefore the polymerization is under 
diffusion control with regard to the NHCBs, which also offsets their molecular reactivity differences.

Conversely, the $\mathrm{O}_{2}$ diffusion is not limiting any more in fluid resins and re-oxygenation occurs during the photopolymerization under air. ${ }^{37}$ At first sight it looks as if this would be detrimental to all NHCBs, which exhibit high reactivity toward oxygen therefore neutering the initiating radicals. However, the high methacrylate concentration in the resin still ensures a correct initiation as the monomer concentration offsets the lower addition rate of the NHC-Boryl radicals. In other words, yes, the NHC-boryl radicals react fast with dioxygen, but there is not enough oxygen to trap them as the solubility of dioxygen in apolar organic solvents is approx. $10^{-3}$ mol. $\mathrm{L}^{-1}$. The rapid reaction rate of dioxygen with the NHC-boryl radicals does not explain why $\mathbf{3}$ is resistant to oxygen inhibition in fluid methacrylic resins, while $\mathbf{1}$ and $\mathbf{2}$ are not.

The growing chains that feature C-radicals are however trapped by the dioxygen present in solution because the $\mathrm{k}_{\mathrm{p}}$ is now much lower than the $\mathrm{k}_{\mathrm{add}}$ of the NHC-Boryl radicals, meaning that oxygen trapping becomes competitive. The propagation of the macroradicals is thus less efficient than their reaction with $\mathrm{O}_{2}$, resulting in polymerization delay or even in no polymerization. To examine that issue we resorted to modeling. 

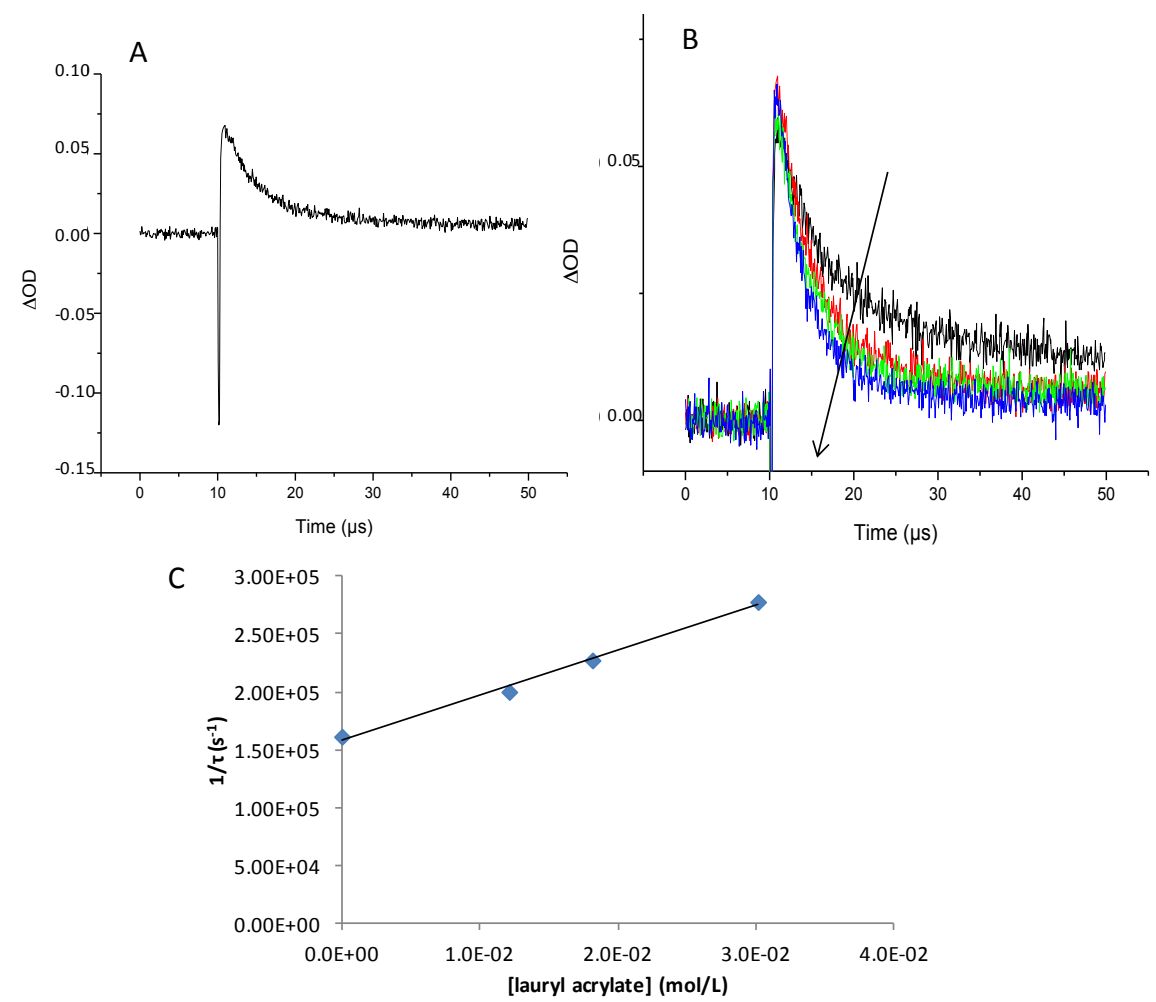

Figure 11. (A) Kinetics at $350 \mathrm{~nm}$ in di-tert-butylperoxide/acetonitrile $(50 \% / 50 \%)$ for 3•; (B) Quenching of radical 3• $([3 \bullet]=0.026 \mathrm{M})$ for lauryl acrylate concentrations ranging from 0 to $0.3 \mathrm{M}$ (laser pulse for $\mathrm{t}=10 \mu$ s for $\mathrm{A}$ and B); and (C) Stern-Volmer quenching data for (B).

c) Molecular Modeling. To get a better understanding of the reactivity of the three NHCBoranes, we performed molecular modeling studies at the uB3LYP/6-31+G* level of theory (see Supporting Information) ${ }^{38}$

- Bond dissociation energies (BDEs): The calculated B-H BDEs of the three NHC-Boranes were found to be similar, albeit slightly weaker for the tetrazolydinene derivative: $80.4 \mathrm{kcal} \mathrm{mol}^{-1}$ 
for $1 ; 80.3 \mathrm{kcal} \mathrm{mol}^{-1}$ for $2 ; 79.2 \mathrm{kcal} \mathrm{mol}^{-1}$ for 3 . These results correlate well with the LFP observations: all NHC-boranes considered react with the polarly matched $t$-butoxyl radical at approximately the same rate $\left(\right.$ see $\mathrm{k}_{\mathrm{H}}$ rates, Table 1$)$.

- Single-Occupied Molecular Orbitals (SOMOs) and boron spin density: The calculated SOMOs of NHC-boryl radicals $\mathbf{1 \bullet - 3 \bullet}$ are similar (see Figure S12), but the spin density at boron was different: it went down from 0.55 for $1 \bullet$, to 0.53 for $2 \bullet$ and 0.52 for $3 \bullet$. The higher the number of nitrogen atoms, the smaller the spin density on the boron atom. Conversely, the spin density of the proximal (carbene) carbon grew from 0.22 in $\mathbf{1} \bullet$ to 0.27 in $\mathbf{2} \bullet$ and 0.31 for $\mathbf{3}$.

- Enthalpies of recombination of the NHC-Boryl radicals with dioxygen: The reaction enthalpies of the NHC-boryl radicals with dioxygen (eq. 3) as well of the reaction of the adduct bora-peroxyl radicals with NHC-boranes (eq. 5) were calculated next. Indeed, these two reactions provide a path to overcome oxygen inhibition of the radical polymerization. ${ }^{24}$

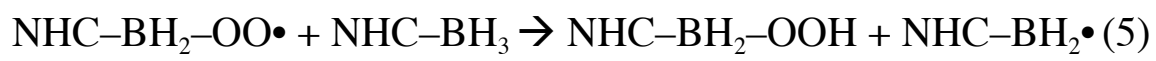

In equation 3 , the reaction was found to be more exothermic with $1 \bullet\left(-79.1 \mathrm{kcal} . \mathrm{mol}^{-1}\right)$ that with $2 \bullet\left(-77.8 \mathrm{kcal}_{\mathrm{mol}}{ }^{-1}\right)$ and, especially, $3 \bullet\left(-75.8 \mathrm{kcal} . \mathrm{mol}^{-1}\right)$. In contrast, while all hydrogen transfers to the bora-peroxyl radicals are almost thermoneutral, only with $\mathbf{3}$ it is an exothermic process $\left(\Delta \mathrm{H}=-0.4 \mathrm{kcal} . \mathrm{mol}^{-1}\right.$ vs. $2.1 \mathrm{kcal} . \mathrm{mol}^{-1}$ for $\mathbf{1}$ and $1.4 \mathrm{kcal} . \mathrm{mol}^{-1}$ for 2$)$.

- Electronegativities and charge-transfer abilities of NHC-boryl radicals: The Mulliken electronegativity of the three NHC-boryl radicals was determined using Parr and Pearson's model (Eq 6a). The latter uses the ionization potential (IP) and the electron affinity (EA) of the radicals, which can be calculated (DFT level). The data are summarized in Table 2. We noticed 
that the electronegativity increased with the number of nitrogen atom of the NHC-borane molecule (from $2.72 \mathrm{eV}$ in $\mathbf{1} \bullet$ to $3.12 \mathrm{eV}$ in $\mathbf{2 \bullet}$ and $3.54 \mathrm{eV}$ in $\mathbf{3 \bullet}$ ). We then calculated the transition states for the addition of NHC-boryl radicals $\mathbf{1} \cdot \mathbf{3} \cdot$ onto methyl acrylate (MA, at the uB3LYP/6-31+G* level of theory, Figures 12 and S13a, Table 2), and focused on the charge transfer from the electronegative radicals to MA in the transition state ( $\delta$, eqs. $6 \mathrm{~b}$ and $6 \mathrm{c})$. We used $4.655 \mathrm{eV}$ and $5.145 \mathrm{eV}$ for the $\chi$ and hardness $\eta$ value of MA, respectively.

$$
\begin{aligned}
& \chi=1 / 2 \times(\mathrm{IP}+\mathrm{EA}) \\
& \eta=1 / 2(\mathrm{IP}-\mathrm{EA}) \\
& \delta=1 / 2\left(\chi_{\mathrm{MA}}-\chi_{\mathrm{R} \cdot}\right) /\left(\eta_{\mathrm{MA}}+\eta_{\mathrm{R} \cdot}\right)
\end{aligned}
$$

In all cases, the calculations clearly indicated electron transfer from the NHC-boryl radicals to the monomer in the transition state (positive values) in agreement with their nucleophilic radical character.

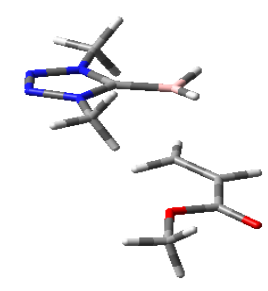

Figure 12. Structure of the transient state resulting of the addition of $\mathbf{3} \bullet$ onto methyl acrylate, (geometry optimized at the uB3LYP/6-31+G* level).

That makes all the NHC-Boryl radicals nucleophilic and well suited for a fast addition to electron-poor monomers. ${ }^{36,39}$ However, with a charge transfer of only $+0.07 \mathrm{eV}, \mathbf{3} \bullet$ is noticeably 
less nucleophilic than $\mathbf{1} \cdot(+0.12 \mathrm{eV})$. This correlates well with the LFP observation that $\mathbf{3}$ is a less reactive hydride than $\mathbf{1}$. Both reactivities are conditioned by the $\sigma$-donating ability of the NHCs, which is lower in the tetrazolydinene series. Finally, using the Evans-Polanyi principle we studied the state correlation diagram and the activation barrier $\left(\mathrm{E}_{\mathrm{a}}\right)$ for all three additions (Table 2 and Figure S13b). We found that the activation energy of the addition increases with the number of nitrogen atom on the NHC, from $3.9 \mathrm{kcal}^{\mathrm{mol}}{ }^{-1}$ in $\mathbf{1}$ to $5.4 \mathrm{kcal}_{\mathrm{mol}}{ }^{-1}$ in $\mathbf{3}$. This is again consistent with the rates experimentally measured by LFP.

Table 2. Energetic parameters characterizing the charge-transfer configurations involved in the addition reaction of NHC-boryl onto MA at the $\mathrm{uB} 3 \mathrm{LYP} / 6-31+\mathrm{G}^{*}$ level.

\begin{tabular}{|l|c|c|c|c|c|c|}
\hline Radical & $\begin{array}{c}\mathrm{E}_{\mathrm{a}} \\
\left(\mathrm{kcal} \mathrm{mol}^{-1}\right)\end{array}$ & IP $(\mathrm{eV})$ & EA $(\mathrm{eV})$ & $\begin{array}{c}\text { Electronegativ } \\
\text { ity } \chi(\mathrm{eV})\end{array}$ & $\begin{array}{c}\text { Hardness } \\
\eta(\mathrm{eV})\end{array}$ & $\begin{array}{c}\text { Charge } \\
\text { transfer } \delta\end{array}$ \\
\hline $\mathbf{1 \bullet}$ & 3.9 & 5.39 & 0.054 & 2.72 & 2.67 & $+0.12 \mathrm{e}^{-}$ \\
\hline $\mathbf{2 \bullet}$ & 4.6 & 5.88 & 0.363 & 3.12 & 2.76 & $+0.10 \mathrm{e}^{-}$ \\
\hline $\mathbf{3 \bullet}$ & 5.4 & 6.39 & 0.684 & 3.54 & 3.54 & $+0.07 \mathrm{e}^{-}$ \\
\hline
\end{tabular}

-What the modeling suggests for oxygen inhibition. The subtle change in the spin distribution of the NHC-boryl radicals is a first factor that could contribute to the decreased addition rate of 3• onto both acrylates and dioxygen. The delocalization into the carbene is higher in $\mathbf{3 \bullet}$, which is more thermodynamically stabilized, therefore less reactive. This is further supported if one considers that the bora-peroxyl radicals obtained after trapping of $\mathbf{1} \cdot \mathbf{- 3} \bullet$ by dioxygen have no meaningful spin density differences (see Table S1) and therefore have all roughly the same 
thermodynamic stabilities, which suggests that the difference observed stems from the initial radicals. However, the overall rate for oxygen trapping are high. Also, the spin densities on the oxygen atoms are all slightly lower than that of an organic peroxyl radicals (0.64-0.65 vs. 0.69), and much too small to allow addition to the monomer (and therefore O-based initiation).

The resistance induced by NHCBs to oxygen inhibition is also due to the fast reaction that occurs between the peroxyl radicals formed after $\mathrm{O}_{2}$ trapping of the growing macro-radicals and remaining hydrides on the boron atoms. That leads to the formation of new initiating NHC-boryl radicals. ${ }^{4}$ This reaction is exothermic only for $\mathbf{3}$, making it a more rapid $\mathrm{H}$-atom-transferring "healer" than $\mathbf{1}$ or $\mathbf{2}$. We believe this is the true reason why $\mathbf{3}$ is better at photopolymerizing resins in the presence of air.

\section{Conclusions}

In this article, we report the visible-light photopolymerization of methacrylates using an improved water-compatible NHC-Borane that is also more resistant to dioxygen than the previous generation of NHC-Boranes we introduced, that failed for these visible-light photopolymerizations under air. One can now photopolymerize all kinds of resins, in particular the oxygen-inhibition-sensitive fluid ones as well as access hydrogels with the same PIS. That the Boron-based PISs can work in both aqueous and non-aqueous conditions is a noticeable advantage over the purely hydrophobic camphorquinone-based system. The tetrazolydineneborane we introduce compares well to the latter in organic media but overperforms in aqueous ones. Modeling and physico-chemical characterizations allowed us to propose a structure/reactivity relationship that explains the better performance of the tetrazolydinene- 
borane. Further work will focus on further extending the scope of the Boron-based photoinitiation to longer wavelengths.

\section{ASSOCIATED CONTENT}

Supporting Information. Synthetic details for the preparation and characterization of NHCB 3, polymer characterizations and modeling details.

\section{AUTHOR INFORMATION}

\section{Corresponding Author}

*emmanuel.lacote@univ-lyon1.fr; jacques.lalevee@uha.fr

\section{Author Contributions}

The manuscript was written through contributions of all authors. All authors have given approval to the final version of the manuscript.

\section{Funding Sources}

Université Claude Bernard Lyon 1, CNRS, CPE Lyon, UHA and ANR (grant Photo-B)

\section{ACKNOWLEDGMENT}

DS acknowledges Université Claude Bernard for a graduate fellowship.

\section{REFERENCES}

(1) Liu, S.; Cheng, Y.; Zhang, H.; Qiu, Z.; Kwok, R. T. K.; Lam, J. W. Y.; Tang, B. Z. In Situ Monitoring of RAFT Polymerization by Tetraphenylethylene-Containing Agents with Aggregation-Induced Emission Characteristics. Angew. Chem. Int. Ed. 2018, 57, 6274-6278. 
(2) Shanmugam, S.; Xu, S.; Adnan, N. N. M.; Boyer, C. Heterogeneous Photocatalysis as a Means for Improving Recyclability of Organocatalyst in "living" Radical Polymerization. Macromolecules 2018, 51, 779-790.

(3) Gomez, M. L.; Gallastegui, A.; Spesia, M. B.; Montejano, H. A.; Williams, R. J.; Previtali, C. M. Synthesis of poly(HEMA-co-AAm) hydrogels by visible-light photopolymerization of aqueous solutions containing aspirin or ibuprofen: analysis of the initiation mechanism and the drug release. Polym. Adv. Technol. 2017, 28, 435-442.

(4) Xu, J.; Shanmugam, S.; Fu, C.; Aguey-Zinsou, K.-F.; Boyer, C. Selective Photoactivation: From a Single Unit Monomer Insertion Reaction to Controlled Polymer Architectures. J. Am. Chem. Soc. 2016, 138, 3094-3106.

(5) McKenzie, T. G.; Wong, E. H. H.; Fu, Q.; Sulistio, A.; Dunstan, D. E.; Qiao, G. G. Controlled Formation of Star Polymer Nanoparticles via Visible Light Photopolymerization. ACS Macro Lett. 2015, 4, 1012-1016.

(6) For a very recent example of light-controlled catalyzed polymerization, see: Ravetz, B. D.; Ruhl, K. E.; Rovis, T. External Regulation of Cobalt-Catalyzed Cycloaddition Polymerization with Visible Light. ACS Catal. 2018, 8, 5323-5327.

(7) For a seminal contribution, see: Yagci, Y.; Hepuzer, Y. A Novel Visible Light Initiatiating System for Cationic Polymerization Macromolecules 1999, 32, 6367-6370.

(8) Terasawa, H.; Tan, F.; Sugihara, O.; Kawasaki, A.; Inoue, D.; Yamashita, T.; Kagami, M.; Maury, O.; Bretonnière, Y.; Andraud, C. Light-induced self-written waveguide fabrication using 1550 nm laser light. Opt. Lett. 2017, 42, 2236-2238.

(9) Al Mousawi, A.; Garra, P.; Schmitt, M.; Toufaily, J.; Hamieh, T.; Graff, B.; Fouassier, J. P.; Dumur, F.; Lalevée, J. 3-Hydroxyflavone and N-Phenylglycine in High Performance Photoinitiating Systems for 3D Printing and Photocomposites Synthesis. Macromolecules 2018, 51, 4633-4641.

(10) Zhang, J.; Dumur, F.; Xiao, P.; Graff, B.; Bardelang, D.; Gigmès, D.; Fouassier, J. P.; Lalevée, J. Structure Design of Naphthalimide Derivatives: Toward Versatile Photoinitiators for Near-UV/Visible LEDs, 3D Printing, and Water-Soluble Photoinitiating Systems. Macromolecules 2015, 48, 2054-2063.

(11) Fouassier, J. P.; Lalevée, J. Photoinitiators for Polymer Synthesis: Scope, Reactivity, and Efficiency; Wiley-VCH: Weinheim, 2012. 
(12) For earlier approaches, see: Lee, C.; Hall, H. K, Jr. Photocopolymerizations of electron-rich olefins with electron-poor olefins by irradiation of their EDA complexes. Macromolecules 1989, $22,21-25$.

(13) Moussa, K.; Decker, C. Light-induced polymerization of new highly reactive acrylic monomers. J. Polym. Sci., Part A: Polym. Chem. 1993, 31, 2197-2203.

(14) Dietliker, K. A Compilation of Photoinitiators: Commercially Available for UV Today; SITA Technology Ltd.: Edinburgh, London, 2002.

(15) Andersson, H.; Gedde, U. W.; Hult, A. Synthesis and Polymerization of Liquid Crystalline Donor-Acceptor Monomers. Macromolecules 1996, 29, 1649-1654.

(16) Curran, D. P.; Solovyev, A.; Makhlouf Brahmi, M.; Fensterbank L.; Malacria M.; Lacôte E. Synthesis and Reactions of N-Heterocyclic Carbene Boranes. Angew. Chem. Int. Eng. 2011, 50, 10294-10317.

(17) Tehfe, M.-A.; Makhlouf Brahmi, M.; Fouassier, J.-P.; Curran, D. P.; Malacria, M.; Fensterbank, L.; Lacôte, E.; Lalevée, J. N-Heterocyclic Carbenes-Borane Complexes: A New Class of Initiators for Radical Photopolymerization. Macromolecules 2010, 43, 2261-2267.

(18) Lalevée, J.; Telitel, S.; Tehfe, M. A.; Fouassier, J. P.; Curran, D. P.; Lacôte, E. NHeterocyclic Carbene Boranes Accelerate Type I Radical Photopolymerizations and Overcome Oxygen Inhibition. Angew. Chem. Int. Ed. 2012, 51, 5958-5961.

(19) Telitel, S.; Schweizer, S.; Morlet-Savary, F.; Graff, B.; Tschamber, T.; Blanchard, N.; Fouassier, J. P.; Lelli, M.; Lacôte, E.; Lalevée, J. Soft Photopolymerizations Initiated by DyeSensitized Formation of NHC-Boryl Radicals under Visible Light. Macromolecules 2013, 46, 43-48.

(20) Telitel, S.; Vallet, A.-L.; Schweizer, S.; Delpech, B.; Blanchard, N.; Morlet-Savary, F.; Graff, B.; Curran, D. P.; Robert, M.; Lacôte, E.; et al. Formation of N-Heterocyclic CarbeneBoryl Radicals through Electrochemical and Photochemical Cleavage of the B-S bond in NHeterocyclic Carbene-Boryl Sulfides. J. Am. Chem. Soc. 2013, 135, 16938-16947.

(21) Tehfe, M.-A.; Monot, J.; Malacria, M.; Fensterbank, L.; Fouassier, J.-P.; Curran, D. P.; Lacôte, E.; Lalevée, J. A Water-Compatible NHC-Borane: Photopolymerizations in Water and Rate Constants for Elementary Radical Reactions. ACS Macro Lett. 2012, 1, 92-95. 
(22) Le Quéméner, F.; Subervie, D.; Morlet-Savary, F.; Lalevée, J.; Lansalot, M.; BourgeatLami, E.; Lacôte, E. Visible-Light Emulsion Photopolymerization of Styrene. Angew. Chem. Int. Ed. 2018, 57, 957-961.

(23) For another approach of visible-light photopolymerization in emulsion, see: Fan, W.; Tosaka, M.; Yamago, S.; Cunningham, M. F. Living Ab Initio Emulsion Polymerization of Methyl Methacrylate in Water Using a Water-Soluble Organotellurium Chain Transfer Agent under Thermal and Photochemical Conditions. Angew. Chem. Int. Ed. 2018, 57, 962-966.

(24) Tehfe, M.-A.; Monot, J.; Brahmi, M. M.; Bonin-Dubarle, H.; Curran, D. P.; Malacria, M.; Fensterbank, L.; Lacôte, E.; Lalevée, J.; Fouassier, J.-P. N-Heterocyclic carbene-borane radicals as efficient initiating species of photopolymerization reactions under air. Polym. Chem. 2011, 2, 625-631.

(25) Ueng, S.-H.; Fensterbank, L.; Lacôte, E.; Malacria, M.; Curran, D. P. Radical Deoxygenation of Xanthates and Related Functional Groups with New Minimalist NHeterocyclic Carbene Boranes. Org. Lett. 2010, 12, 3002-3005.

(26) Schaper, L.-A.; Wei, X.; Altmann, P. J.; Öfele, K.; Pöthig, A.; Drees, M.; Mink, J.; Herdtweck, E.; Bechlars, B.; Herrmann, W. A.; et al. Synthesis and Comparison of Transition Metal Complexes of Abnormal and Normal Tetrazolylidenes: A Neglected Ligand Species. Inorg. Chem. 2013, 52, 7031-7044.

(27) Foresman, J.; Frish, Æ. Exploring Chemistry with Electronic Structure Methods; Gaussian Inc.: Pittsburgh, 1996.

(28) Murov, S. L. in Handbook of Photochemistry; Marcel Dekker: New York, 1973.

(29) Lalevée, J.; Allonas, X.; Fouassier, J.-P. N-H and $\alpha(\mathrm{C}-\mathrm{H})$ Bond Dissociation Enthalpies of Aliphatic Amines. J. Am. Chem. Soc. 2002, 124, 9613-9621.

(30) Bouaouina, B.; Besnard, A.; Abaidia, S. E.; Airoudj, A.; Bensouici, F. Correlation between mechanical and microstructural properties of molybdenum nitride thin films deposited on silicon by reactive R.F. magnetron discharge. Surf. Coat. Technol. 2018, 333, 32-38.

(31) Sader, J. E.; Chon, J. W. M.; Mulvaney, P. Calibration of rectangular atomic force microscope cantilevers. Rev. Sci. Instrum. 1999, 70, 3967-3969.

(32) Morlet-Savary F.; Klee J. E.; Pfefferkorn F.; Fouassier J. P.; Lalevée J. The Camphorquinone/Amine and Camphorquinone/Amine/Phosphine Oxide Derivative 
Photoinitiating Systems: Overview, Mechanistic Approach, and Role of the Excitation Light Source. Macromol. Chem. Phys. 2015, 216, 2161-2170.

(33) Bouzrati-Zerelli M.; Maier M.; Fik C. P; Dietlin C.; Morlet-Savary F.; Fouassier J. P.; Klee J. E; Lalevée J. A low migration phosphine to overcome the oxygen inhibition in new high performance photoinitiating systems for photocurable dental type resins Polym. Int. 2017, 66, 504-511.

(34) Zivic, N.; Zhang, J.; Bardelang, D.; Dumur, F.; Xiao, P.; Jet, T.; Versace, D.-L.; Dietlin, C.; Morlet-Savary, F.; Graff, B.; et al. Novel naphthalimide-amine based photoinitiators operating under violet and blue LEDs and usable for various polymerization reactions and synthesis of hydrogels. Polym. Chem. 2016, 7, 418-429.

(35) Taniguchi, T.; Curran, D. P. Silica Gel Promotes Reductions of Aldehydes and Ketones by N-Heterocyclic Carbene Boranes. Org. Lett. 2012, 14, 4540-4543.

(36) Telitel, S.; Vallet, A.-L.; Flanigan, D. M.; Graff, B.; Morlet-Savary, F.; Rovis, T.; Lalevée, J.; Lacôte, E. Influence of Electronic Effects on the Reactivity of Triazolylidene-Boryl Radicals: Consequences for the use of N-Heterocyclic Carbene Boranes in Organic and Polymer Synthesis. Chem. Eur. J. 2015, 21, 13772-13777.

(37) Lee, T. Y.; Guymon, C. A.; Jönsson, E. S.; Hoyle, C. E. The effect of monomer structure on oxygen inhibition of (meth)acrylates photopolymerization. Polymer 2004, 45, 6155-6162.

(38) Lalevée, J.; Allonas, X.; Fouassier, J.-P. Reactivity of Carbon-Centered Radicals toward Acrylate Double Bonds: Relative Contribution of Polar vs Enthalpy Effects. J. Phys. Chem. A 2004, 108, 4326-4334.

(39) Ueng, S.-H.; Solovyev, A.; Yuan, X.; Geib, S. J.; Fensterbank, L.; Lacôte, E.; Malacria, M.; Newcomb, M.; Walton, J. C.; Curran, D. P. N-Heterocyclic Carbene Boryl Radicals: A New Class of Boron-Centered Radical. J. Am. Chem. Soc. 2009, 131, 11256-11262. 